\title{
Specific IgG subclass antibody pattern to Aspergillus fumigatus in patients with cystic fibrosis with allergic bronchopulmonary aspergillosis (ABPA)
}

\author{
M Skov, T Pressler, H E Jensen, N Høiby, C Koch
}

\begin{abstract}
Background-IgG and IgG subclass antibodies to Aspergillus fumigatus (A fumigatus) were measured in a large population of patients with cystic fibrosis to elucidate a putative antibody pattern specific for allergic bronchopulmonary aspergillosis (ABPA).
\end{abstract}

Methods-An ELISA technique using water soluble somatic hyphal (WSSH) $A$ fumigatus antigens and subclass specific monoclonal antibodies was used for cross sectional quantification of IgG and IgG $_{1-4}$ subclass antibody levels in the serum of 238 patients with cystic fibrosis and 107 healthy controls.

Results-In patients with cystic fibrosis persistently colonised with $A$ fumigatus the subclass antibody levels were significantly increased compared with patients with cystic fibrosis never or rarely colonised $(p<0.001)$. The group of patients persistently colonised with $A$ fumigatus with ABPA (+Af+ABPA) had significantly increased levels of IgG antibodies to $A$ fumigatus (Af-IgG) (median 69 ELISA units (EU) versus 31 ) and of subclasses Af-IgG (91 versus 27), Af-IgG $_{2}$ (143 versus

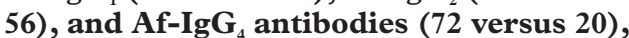
but not of $\operatorname{IgG}_{3}$ (17 versus 15), compared with the colonised patients without ABPA (+Af-ABPA). Patients with cystic fibrosis with no or only rare isolates of $A$ fumigatus without ABPA (-Af-ABPA) also had significantly increased subclass antibody levels (Af-IgG 9 versus 3, Af-IgG 28 versus $5, \mathrm{Af}^{-\mathrm{IgG}_{4}} 16$ versus $4 ; \mathrm{p}<0.001$ ) compared with healthy controls. Low, although detectable, levels of antibodies were demonstrated in healthy controls. ABPA seemed to occur independently of Pseudomonas aeruginosa infection. Using diagnostic cut off levels for ABPA, sensitivity and specificity were calculated. The highest specificity was found for IgG $_{4}$ $(88 \%)$; sensitivity was between $65 \%$ and $73 \%$. The positive predictive values (PPV) were moderate, whereas the negative predictive values (NPV) were high $(96 \%$ in all subclasses except IgG $_{3}$ with 94\%). PPV increased to $\mathbf{5 0 \%}$ if $\mathrm{IgG}_{\mathbf{1}}$ as well as $\mathrm{IgG}_{2}$ and IgG $_{4}$ were included.

Conclusions-In a large number of unselected patients with cystic fibrosis significantly increased levels of Af-specific antibodies belonging to total IgG and all four subclasses were found in all groups of patients compared with healthy controls. In patients persistently colonised with $\boldsymbol{A}$ fumigatus these levels were significantly higher than in non-colonised patients, and the significantly highest levels (with the exception of $\mathrm{IgG}_{3}$ ) were found in patients with ABPA. Using a sensitive ELISA technique, measurements of IgG and IgG subclass antibodies to $A$ fumigatus might be of importance in the management of ABPA, especially as a screening test to exclude the presence of ABPA; other tests are needed to confirm the diagnosis.

(Thorax 1999;54:44-50)

Keywords: cystic fibrosis; allergic bronchopulmonary aspergillosis; IgG subclass antibodies

Colonisation of the lower respiratory tract with A fumigatus is particularly frequent in patients with cystic fibrosis in whom an incidence of $57 \%{ }^{1}$ and a prevalence of $40 \%{ }^{2}$ have been reported. A sizeable minority, ranging from $1 \%$ to $11 \%$ in various reports, develop allergic bronchopulmonary aspergillosis (ABPA). ${ }^{13}$ The diagnosis of ABPA in patients with cystic fibrosis is more difficult than in other patients because several clinical and paraclinical findings are similar to those caused by the more frequent bacterial infections, and by atopy which is present in up to $27 \%$ of patients with cystic fibrosis. ${ }^{1}$ It would therefore be valuable to obtain improved diagnostic tools for the early and specific diagnosis of ABPA in patients with cystic fibrosis. Interaction of specific IgG and IgE antibodies with $A$ fumigatus antigens in the bronchial tree leads to activation of complement and mast cells resulting in mediator release and cytokine production, contributing to lung damage. ${ }^{3}$ We have previously demonstrated that the distribution of antiPseudomonas aeruginosa antibodies among the four IgG subclasses is related to the degree of lung damage in patients with cystic fibrosis and chronic $P$ aeruginosa infection. ${ }^{4}$ As an initial step we therefore undertook the present comprehensive study of specific total IgG and subclasses $\operatorname{IgG}_{1-4}$ antibodies to $A$ fumigatus in 238 unselected patients with cystic fibrosis and related the findings to the degree of colonisation with $A$ fumigatus and to the presence and absence of ABPA. 
Methods

PATIENTS

The diagnosis of cystic fibrosis was based on abnormal sweat electrolytes, cystic fibrosis specific mutations, and typical clinical appearance. All patients are seen on a regular monthly basis in the Danish Cystic Fibrosis Centre. At each visit the clinical condition, pulmonary function, and sputum microbiology including plating on Sabaraud maltose agar to detect fungal growth are assessed. Serological parameters such as eosinophil count, IgE, Af-IgE (Radio Allergo Sorbent Test, RAST), precipitating antibodies to $A$ fumigatus, and immunoglobulins $\mathrm{G}, \mathrm{A}$ and $\mathrm{M}$ are measured at least once a year. Data have thus been recorded prospectively since 1970 .

Based on data obtained over a five year period (1990-1994), all patients with cystic fibrosis were divided into three groups. Group 1: ABPA (+Af+ABPA), patients with cystic fibrosis persistently colonised with $A$ fumigatus and with ABPA (median age 16.5 years (range 9-37), $\mathrm{n}=26$ ); group 2: non-ABPA (+AfABPA), patients with cystic fibrosis persistently colonised but without ABPA (median age 19 years (range 9-44), $\mathrm{n}=35$ ); and group 3: non-A fumigatus (-Af-ABPA), patients with cystic fibrosis with no or only rare isolates of $A$ fumigatus (median age 18 years (range $1-45$ ), $\mathrm{n}$ $=177)$. The results were compared with healthy controls (group 4), a normal healthy control population aged $1-75$ years $(n=107)$ from the serum bank at the Department of Clinical Microbiology, National University Hospital.

All serum samples from the cystic fibrosis patients were obtained within one year (1995) and with a few exceptions during the winter and stored at $-20^{\circ} \mathrm{C}$ until use.

DIAGNOSIS OF ABPA

The "golden standard" diagnostic criteria for ABPA are, according to Nelson" : (1) radiological pulmonary infiltrates, (2) wheezing, (3) positive Aspergillus cultures, (4) positive immediate type reaction by epidermal skin test with A fumigatus, (5) increased serum levels of total IgE, (6) increased serum levels of $A$ fumigatus specific IgE, and (7) increased serum levels of A fumigatus precipitating antibodies. Pulmonary infiltrates and wheezing are, however, extremely common in cystic fibrosis, and atopy, including presence of $A$ fumigatus specific IgE, is more frequent than in the background population. The specificity of these criteria is therefore low in patients with cystic fibrosis. In the present study we therefore defined ABPA as the persistent presence of $A$ fumigatus in lower tract secretions, combined with persistent abnormally raised titres of $A$ fumigatus specific $\operatorname{IgE}$ and precipitating antibodies over the five year observation period. $A$ fumigatus specific precipitating antibodies, expressed as titre, were measured at the Department of Clinical Microbiology, University Hospital, Aarhus (normal value $\leqslant 2^{5}$ ) and specific $A$ fumigatus IgE antibodies were measured at the Laboratory of Medical Allergology,
National University Hospital, Copenhagen (normal value, RAST class $0^{6}$ ).

Diagnostic cut off levels for the diagnosis of ABPA were determined for IgG and IgG subclass antibodies.

PREPARATION OF A FUMIGATUS ANTIGEN

Following the disintegration of mycelial mats of A fumigatus strain ATCC 42202 in an X-press operated at a maximal force of $200 \mathrm{MPa}$ at $-30^{\circ} \mathrm{C}$, preparation of water soluble somatic hyphal (WSSH) antigens were prepared as described previously. ${ }^{7}$ The protein concentration was measured using a refractometer (TS meter, AO Scientific Instruments, Alabama, USA). The antigen preparation was stored (from 1992 until use (1996)) at $-80^{\circ} \mathrm{C}$.

ELISA

ELISA assays similar to those used previously in our laboratory were established. ${ }^{8}$ Irradiated 96-well polystyrene microtitre plates (NuncImmuno-Plate, Maxisorb, Nunc, Denmark) and reagent volumes of $100 \mu \mathrm{l}$ were used. All incubation steps were carried out at $22^{\circ} \mathrm{C}$. Between each step the plates were washed in phosphate buffer saline (PBS) with $0.1 \%$ Tween 20 (Bie \& Berntsen, Denmark), pH 7.2. Antigen was diluted 1:10 000 for IgG and $1: 1000$ for IgG subclasses in PBS and incubated for one hour $(0.5 \mu \mathrm{g}$ of protein per well for IgG and $5.1 \mu \mathrm{g}$ per well for IgG subclasses) at room temperature $\left(22^{\circ} \mathrm{C}\right)$. The samples for IgG measurements reacted overnight (18 hours) at $5^{\circ} \mathrm{C}$ after coating. Additional binding sites in the wells were blocked with the PBS, $0.1 \%$ Tween 20 . Serum samples were diluted 1:4000 for IgG measurements. IgG subclass samples were incubated with antigen for an hour and blocked with PBS and serum in a dilution of 1:400 before they were allowed to react overnight at $22^{\circ} \mathrm{C}$. Peroxidase-conjugated rabbit anti-human IgG specific for gamma chains (Dako, Denmark) and mouse monoclonal anti-human $\operatorname{IgG}_{1-4}$ conjugated to horse radish peroxidase (HRP) (Central Laboratorium of the Red Cross, The Netherlands) were added and incubated for one hour. The specific antibodies were diluted $1: 10000$ for $\mathrm{IgG}$, 1:60 000 for $\operatorname{IgG}_{1}, 1: 3000$ for $\operatorname{IgG}_{2}, 1: 2000$ for $\mathrm{IgG}_{3}$, and $1: 20000$ for $\mathrm{IgG}_{4}$. To each well $1,2-$ phenylenediamine solution $(0.1 \mathrm{M}$ citric acidphosphate buffer, pH 5.0; Dako, Denmark) containing $5 \mu \mathrm{H}_{2} \mathrm{O}_{2}$ per plate was added. After incubation for one hour the reaction was stopped by adding $\mathrm{H}_{2} \mathrm{SO}_{4}(1 \mathrm{M})$. The optical density (OD) was measured using an ELISA plate reader (492 nm, Bio-rad, Japan). All measurements were performed in duplicate. The antigen concentration and serum and antibody dilutions used in the present assays were chosen from serial dilutions carried out in pilot studies. A standard pool of serum from six cystic fibrosis patients colonised with $A$ fumigatus was used for calibration for each plate. A logarithmic curve was drawn from the results of the standard serum in each plate. The values were determined in relation to the curve and expressed in ELISA units (EU). ${ }^{8}$ 


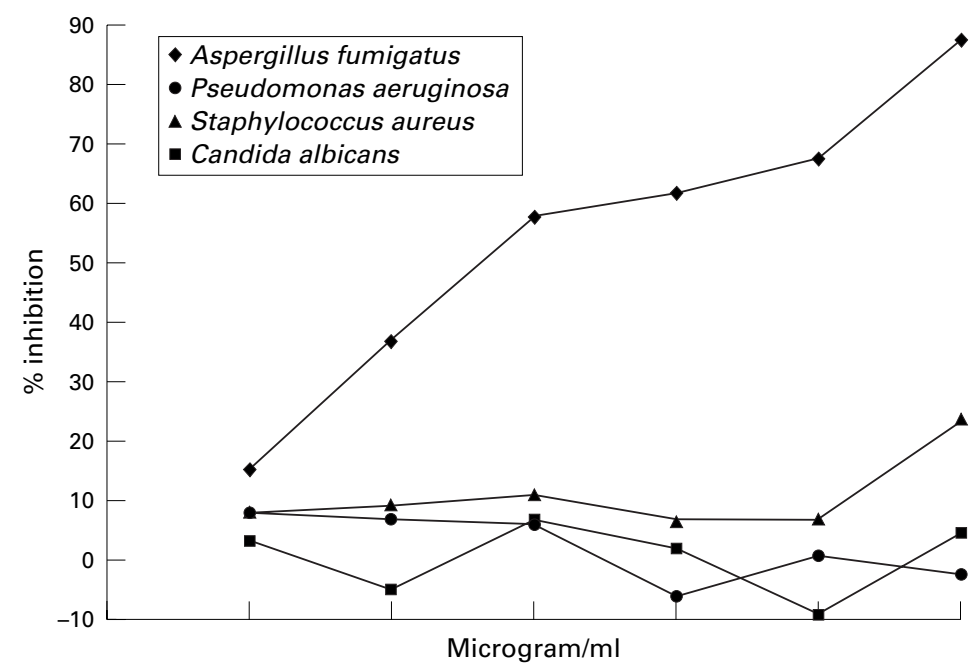

Figure 1 Antigenic specificity of the assay expressed as increasing \% inhibition (decreasing antibody activity) after absorption of the standard serum with increasing amounts of antigen preparations of $A$ fumigatus, $P$ aeruginosa, $S$ aureus, and $C$ albicans.

ASSESSMENT OF ANTIGENIC SPECIFICITY OF THE ASSAY

$P$ aeruginosa and Staphylococcus aureus are common causes of pulmonary infection in patients with cystic fibrosis and most have
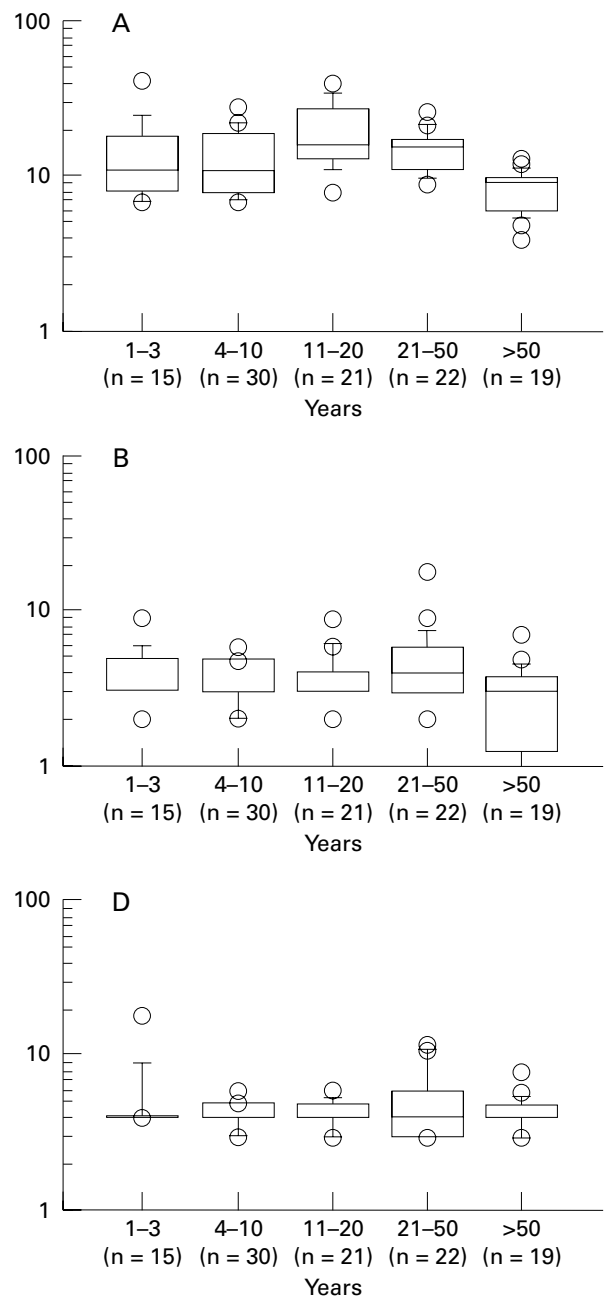

increased specific antibody titres against these organisms. The influence of antibodies to these bacteria on specific Aspergillus antibodies was assessed. Another fungus, Candida albicans, which is known to be present in the lungs of patients with cystic fibrosis, was also absorbed. Standard serum samples diluted 1:10 000 for IgG and 1:1000 for IgG subclasses were absorbed with increasing amounts of sonicated preparations of $P$ aeruginosa, $S$ aureus $^{8}$ (protein A-deficient strain to avoid reaction with the Fc part of $\operatorname{IgG})^{9}$ and $C$ albicans. The absorption was compared with similar absorption performed with $A$ fumigatus antigen.

\section{REPRODUCIBILITY OF THE ASSAY}

Twelve serum samples from cystic fibrosis patients colonised with $A$ fumigatus (samples covering the spectrum from low to high levels) were tested in duplicate in two different plates on two different days. The intraplate, plate-toplate, and day-to-day variations were determined using the formula: standard deviation $(\mathrm{SD})=\left(\Sigma \mathrm{d}^{2} / 2 \mathrm{n}\right)$, where $\Sigma \mathrm{d}^{2}=$ the sum of the squared differences of double determinations of the same sample, and $n=$ the number of observations.

Figure 2 A fumigatus- $\operatorname{Ig} G$ and $\operatorname{Ig} G$ subclass antibody levels in 107 healthy controls. $A=\operatorname{Ig} G, B=\operatorname{Ig} G, C=\operatorname{Ig} G, D=$ $\operatorname{Ig} G_{3}, E=I g G_{4}$. Values are given in ELISA units (EU). The box plots show the 10th, 25th, 50th, 75th, and 90th percentiles. Values above and below are shown separately.
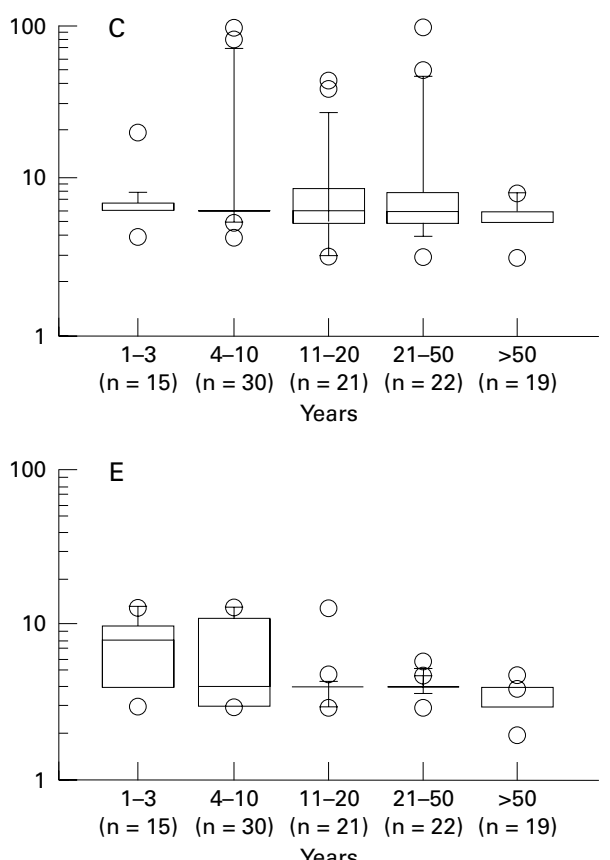

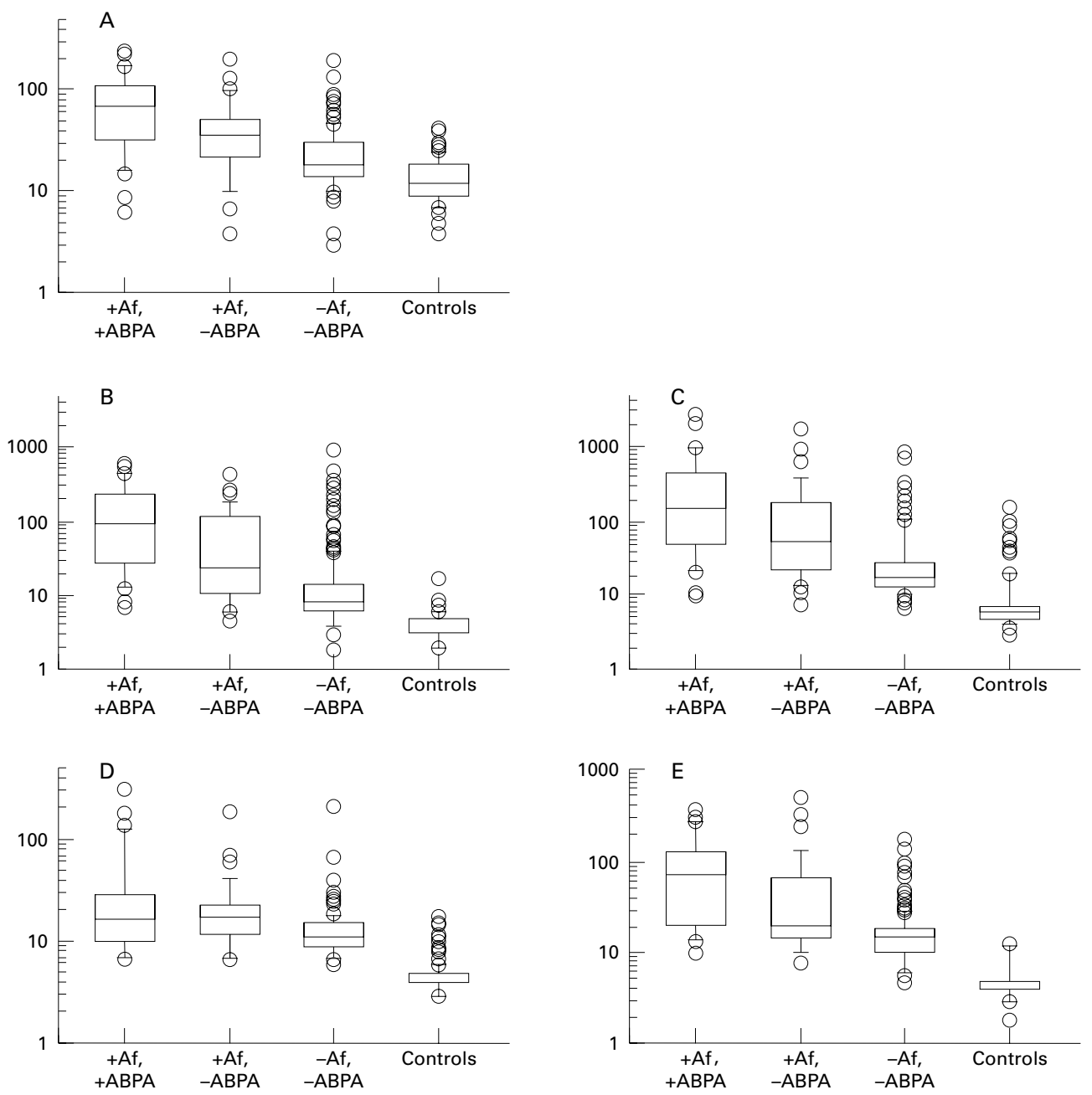

Figure 3 A fumigatus-IgG and IgG subclass antibody levels in $A B P A(+A f+A B P A)$ patients, non-ABPA $(+A f-A B P A)$ patients, non-A fumigatus ( $-A f-A B P A)$ patients, and controls. $A=\operatorname{IgG}, B=\operatorname{Ig} G_{1}, C=\operatorname{Ig} G_{2}, D=\operatorname{Ig} G_{3}, E=\operatorname{Ig} G_{4}$. Values are given in Elisa units (EU). The box plots show the 10th, 25th, 50th, 75th, and 90th percentiles. Values above and below these percentiles are shown separately. $+A f+A B P A(n=26$, median age 18.5 years (range 9-37)); $+A f-A B P A(n=35$, age 19 years (9-44)); $-A f-A B P A(n=177$, age 18 years (1-45)); controls $(n=107$, age 21 years $(1-75))$. The $p$ value between two adjoining groups in each box plot is $p<0.001$ in $\operatorname{IgG}$ and all the subclasses except in $\operatorname{Ig} G_{3}$ (panel $D$ ); $p=0.02$ between $+A f-A B P A$ and $-A f-A B P A ; p=0.8$ between $+A f+A B P A$ and $+A f-A B P A$.

ANALYSIS OF DATA

Sensitivity (SE), specificity (SP), positive predictive value (PPV), and negative predictive value (NPV) were calculated according to the guidelines from the Workshop on Experimental Methodology. ${ }^{10}$ An optimal diagnostic cut off level for ABPA was determined, giving maximum improvements for diagnostic accuracy, which means improving SE without losing SP, or increasing SP without decreasing SE.

To compare all four groups the nonparametric equivalent of an analysis of variance (the Kruskal Wallis test) was performed. The Mann-Whitney $U$ test for non-parametric unpaired data was used within the groups whenever the Kruskal Wallis test was significant. p values of $<0.05$ were considered significant. The values given are medians (range). For independence the $\chi^{2}$ test was used.

\section{Results}

SPECIFICITY AND REPRODUCIBILITY OF THE ASSAYS

Absorption with increasing amounts of $A$ fumigatus antigen resulted in decreased antibody activity (increased inhibition) in IgG as well as $\mathrm{IgG}_{1-4}$ subclasses. Absorption with either $P$ aeruginosa, $S$ aureus, or $C$ albicans antigen resulted in only a minor reduction in the antibody activity (fig 1 ).

The intraplate variation was $15 \%, 10 \%$, $17 \%, 11 \%$, and $17 \%$, respectively, for $\mathrm{IgG}$, $\mathrm{IgG}_{1}, \mathrm{IgG}_{2}, \mathrm{IgG}_{3}$, and $\mathrm{IgG}_{4}$, the interplate variation was $17 \%, 9 \%, 13 \%, 16 \%$, and $14 \%$ and the day-to-day variation was $8 \%, 27 \%, 15 \%$, $10 \%$, and $17 \%$, respectively.

IgG AND IgG SUBCLASS ANTIBODIES TO $A$ FUMIGATUS IN SERUM FROM HEALTHY CONTROLS Low levels of IgG and IgG subclass antibodies to A fumigatus were seen in healthy controls (fig 2).

IgG AND IgG SUBCLASS ANTIBODIES TO $A$ FUMIGATUS IN SERUM FROM PATIENTS WITH CYSTIC FIBROSIS AND HEALTHY CONTROLS Figure 3 shows the levels of IgG and $\operatorname{IgG}_{1-4}$ subclass specific antibodies to $A$ fumigatus in serum samples from patients with cystic fibrosis and controls. In cystic fibrosis patients 


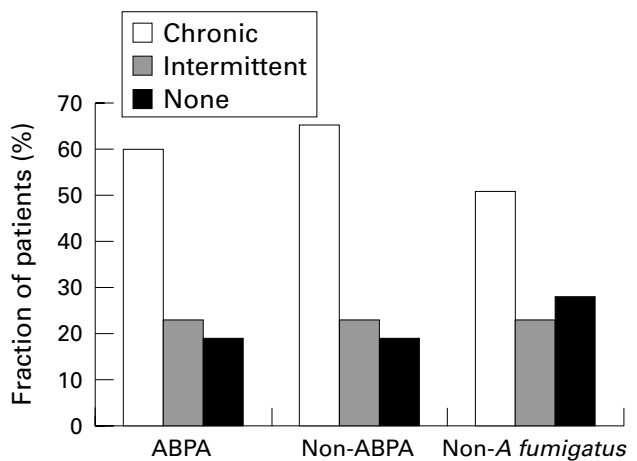

Figure 4 Distribution of chronic, intermittent, or no P aeruginosa infection in the three groups of patients with cystic fibrosis: $A B P A(+A f+A B P A)$, non- $A B P A$ $(+A f-A B P A)$, and non-A fumigatus ( $-A f-A B P A)$

rarely colonised with A fumigatus (group 3) significantly higher $\operatorname{IgG}(\mathrm{p}<0.001)$ as well as $\mathrm{IgG}_{1-4}$ antibody levels $(\mathrm{p}<0.001)$ were observed compared with controls. The most marked increases were observed in patients persistently colonised with $A$ fumigatus (groups 1 and 2). Significantly higher IgG and IgG subclass antibody levels were observed for both groups compared with patients rarely colonised (group $3 ; \mathrm{p}<0.001)$. Patients persistently colonised with $A$ fumigatus with ABPA (group 1) had significantly higher IgG and $\operatorname{IgG}_{1}, \operatorname{IgG}_{2}$, and $\operatorname{IgG}_{4}$ $(p<0.001)$ antibody levels, whereas the $\mathrm{IgG}_{3}$ antibody level was not significantly increased $(\mathrm{p}=0.8)$ compared with persistently colonised patients without ABPA (group 2; fig 3).

SENSITIVITY, SPECIFICITY, PPV AND NPV

Distinction between cystic fibrosis patients with ABPA and those without ABPA (with or without $A$ fumigatus colonisation) was made using diagnostic cut off levels in each IgG subclass antibody. The sensitivity ( $\%$ of patients with ABPA with a positive test), specificity (\% of patients without ABPA with a negative test), positive predictive value (PPV $=\%$ of patients with a positive test with ABPA), and negative predictive value (NPV $=\%$ of patients with a negative test without ABPA) were calculated. The diagnostic cut off levels for ABPA were $\geqslant 40 \mathrm{EU}$ for IgG, $\geqslant 40 \mathrm{EU}$ for $\mathrm{IgG}_{1}, \geqslant 60 \mathrm{EU}$ for $\operatorname{IgG}_{2}, \geqslant 15 \mathrm{EU}$ for $\mathrm{IgG}_{3}$, and $\geqslant 35 \mathrm{EU}$ for $\mathrm{IgG}_{4}$. Sensitivity was calculated to be $69 \%$, $73 \%, 73 \%, 65 \%$, and $73 \%$, respectively, for IgG, IgG $1, \operatorname{IgG}_{2}, \operatorname{IgG}_{3}$, and $\operatorname{IgG}_{4}$, specificity was $82 \%, 85 \%, 77 \%, 67 \%$, and $88 \%$, PPV was $32 \%, 37 \%, 28 \%, 19 \%$, and $43 \%$, and NPV was $96 \%, 96 \%, 96 \%, 94 \%$, and $96 \%$, respectively. The specificity increased to $93 \%$ and the PPV to $50 \%$ if $\operatorname{IgG}_{1}, \operatorname{IgG}_{2}$, and $\operatorname{IgG}_{4}$ were combined.

CORRELATION BETWEEN $P$ AERUGINOSA STATUS AND $A$ FUMIGATUS STATUS

The three groups of cystic fibrosis patients were correlated according to their $P$ aeruginosa status. A possible predisposition to colonisation with $A$ fumigatus in patients chronically colonised with $P$ aeruginosa was examined. The $P$ aeruginosa status was either chronic, intermittent, or none at the time of the study. Chronic $P$ aeruginosa means positive $P$ aeruginosa culture in six succeeding months or shorter if there is a significant increase in specific precipitating antibodies to $P$ aeruginosa $(\geqslant 2)$; intermittent $P$ aeruginosa means positive $P$ aeruginosa culture at least once with normal precipitating antibodies to $P$ aeruginosa $(0-1)$. A similar distribution of chronic colonisation with $P$ aeruginosa was seen in the three groups (group 1 versus $2, \mathrm{p}=0.28$; group 2 versus $3, \mathrm{p}$ $=0.26) ; 60 \%$ in the ABPA group, $65 \%$ in the non-ABPA group, and $51 \%$ in the nonAspergillus group. Intermittent colonisation with $P$ aeruginosa was seen in $23 \%, 23 \%$, and $21 \%$ and no colonisation in $19 \%, 14 \%$, and $28 \%$ in the ABPA, non-ABPA and nonAspergillus groups, respectively (fig 4).

\section{Discussion}

This study demonstrates a specific Af-IgG subclass pattern in cystic fibrosis patients with ABPA (+Af+ABPA), with significantly increased levels of Af-IgG ${ }_{1}, \mathrm{Af}-\mathrm{IgG}_{2}$ and Af-IgG but not $\mathrm{Af}-\mathrm{IgG}_{3}$ compared with non-ABPA (+Af-ABPA) cystic fibrosis patients. Both of these patient groups had significantly increased levels of all Af-IgG subclasses compared with the non-Aspergillus colonised patients with cystic fibrosis (-Af-ABPA). Furthermore, in the latter group significantly higher levels in all four IgG subclasses were found compared with healthy controls. Thus, generally higher levels of IgG and IgG subclass antibodies to A fumigatus were seen in all patients with cystic fibrosis compared with healthy controls of comparable age. Low but detectable levels of all four subclasses of antibodies were found in all the healthy controls.

The highest specificity for the diagnosis of ABPA was reported in subclass $\operatorname{IgG}_{4}(88 \%)$, which increased to $92 \%$ if $\operatorname{IgG}_{1}$ and $\operatorname{IgG}_{2}$ were also included. The PPV was moderate with IgG and the IgG subclasses while the NPV was high $\left(96 \%\right.$, except $94 \%$ in $\left.\mathrm{IgG}_{3}\right)$. With $82 \%$ specificity of total IgG and $96 \%$ NPV, measurements of total IgG alone may be as useful as measurement of the subclasses. Determination of IgG and IgG subclass antibody levels may be particularly valuable as a screening test to exclude the presence of ABPA. Other tests still have to be used to confirm the diagnosis of ABPA.

The assays presently used have high antigen specificity with regard to IgG and the IgG subclasses. With an analytical variation similar to other assays used for the determination of $A$ fumigatus IgG antibodies ${ }^{11}$ or $P$ aeruginosa subclass antibodies, ${ }^{81213}$ the reproducibility was acceptable. The ELISA assays were calibrated with pooled high titre serum samples and therefore the precision of the measurement may decrease slightly with very low levels of antibodies. Most of the serum samples were obtained in the winter time to avoid a possible seasonal variation in exposure to $A$ fumigatus.

In various studies patients with cystic fibrosis have been divided into groups according to increasing positivity to different $A$ fumigatus specific tests. ${ }^{14-16}$ All these studies have shown the same gradual increase of all the IgG subclasses with increasingly positive $A$ fumigatus specific tests, much like the grouping in this 
study. However, our study is a cross sectional study using a much larger number of unselected cystic fibrosis patients. Furthermore, it seems to be the only study in which $\mathrm{Af}-\mathrm{IgG}_{3}$ does not increase significantly from + Af-ABPA patients to +Af-+ABPA patients compared with the other subclasses. The reason for this is unclear.

Most studies of ABPA have been performed in non-cystic fibrosis patients. Comparing non-cystic fibrosis ABPA patients with patients with aspergillomas, asthmatics, and healthy controls, Kurup et al found significantly increased levels of all four subclasses in the ABPA group but lower levels of $\mathrm{Af}-\mathrm{IgG}_{3}$ than the other isotypes. ${ }^{17}$ Similar findings were presented in a study comparing patients with serological signs of ABPA (ABPA-S) and patients with serological ABPA including central bronchiectasis (ABPA-CB). ${ }^{18}$ Af-IgG $_{1}$,

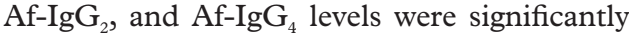
increased in ABPA-CB patients compared with ABPA-S patients while Af- $\operatorname{IgG}_{3}$ levels were similar. ${ }^{18}$

Two smaller studies have suggested that increased levels of Af- $\operatorname{IgG}_{4}{ }^{19}$ or Af-IgG ${ }_{1}$ and Af- $\mathrm{IgG}_{4}{ }^{20}$ are characteristic of ABPA. Even though we found ABPA to be characterised by increased Af- $\operatorname{IgG}_{1}$, Af- $\operatorname{IgG}_{2}$, and Af- $\operatorname{IgG}_{4}$, it was confirmed by the present study that $\mathrm{Af}-\mathrm{IgG}_{4}$ showed highest specificity and that specificity increased if Af-IgG $\mathrm{I}_{1}$ and $\mathrm{Af}-\mathrm{IgG}_{4}$ were both increased.

Interestingly, using the recombinant $A$ fumigatus protein antigen 1/a ( $\mathrm{rAsp}$ f 1/a) Nikolaizik et $a l^{14}$ recently found significantly increased levels of $\operatorname{IgG}_{1}$ and $\operatorname{IgG}_{4}$ in patients with cystic fibrosis with ABPA compared with patients with cystic fibrosis allergic only to Aspergillus. Specific $\operatorname{IgG}_{2}$ and $\mathrm{IgG}_{3}$ levels were, however, not measured.

Demonstration of precipitating antibodies to $A$ fumigatus is the most widely used method for serodiagnosis of ABPA. Thus, only two criteria have been reported to be highly specific for ABPA - namely, raised IgG and IgE antibodies to A fumigatus combined with central bronchiectasis. ${ }^{3}$ The sensitivity of ELISA has the clinical advantage that the presumed pre-injury phase of ABPA may be diagnosed by using IgG and IgE ELISAs and, furthermore, it has been proved to be superior to immunoblotting. ${ }^{4}{ }^{21} 22$ Using the current standard criteria ABPA may not be diagnosed until considerable loss of lung function is present. The prevalence of detectable IgG antibodies to A fumigatus has been reported to increase with age in patients with cystic fibrosis. ${ }^{15}{ }^{23}$ In one study 35 of 50 patients with cystic fibrosis aged 2.5-29 years had measurable IgG antibodies to A fumigatus; all patients over 12 years and none younger than four years had measurable IgG antibodies to $A$ fumigatus. ${ }^{23}$ Accordingly, $84 \%$ of 147 patients with cystic fibrosis aged 5-43 years had serum IgG antibodies to A fumigatus allergen $1 /$ a $(A s p f 1$ ), increasing to $98 \%$ in patients over 10 years. ${ }^{16}$ The low levels of Af-IgG antibodies in healthy controls in the present study are probably due to the ubiquitous presence of the fungus.
An association between $P$ aeruginosa colonisation and the development of ABPA was reported by Nikolaizik et al. ${ }^{14}$ This is in contrast to a previous report, ${ }^{2}$ as well as the present findings, showing that ABPA occurs independently of $P$ aeruginosa infection.

In conclusion, measurements of $\operatorname{IgG}$ and IgG subclass antibodies to $A$ fumigatus, using a multivalent antigen extract and ELISA techniques, may be valuable in the diagnosis of ABPA, especially as a screening test to exclude the diagnosis. Confirmation of the diagnosis still requires other tests. We have shown a specific pattern of significantly increased Af-IgG ${ }_{1}$, Af- $\operatorname{IgG}_{2}$, and Af-IgG , but not Af-IgG $_{3}$, antibody levels in patients with ABPA. Measurement of the $\mathrm{IgG}_{4}$ antibody was most specific in establishing the diagnosis of ABPA. The NPV was high in IgG as well as in all subclasses. Further longitudinal studies of IgG subclass antibodies to follow fluctuations in the levels due to changes in disease activity are needed for appropriate medication. Early diagnosis and treatment of ABPA may be of importance in the prevention of serious and potentially irreversible lung damage.

This study was supported by The Ville Heise Foundation and The Danish Research Councils.

1 Nelson LA, Callerame ML, Schwartz RH. Aspergillosis and topy in cystic fibrosis. Am Rew Respir Dis 1979;20:863-73. 2 Schønheyder H, Jensen T, Høiby N, et al. Frequency of Aspergillus fumigatus isolates and antibodies to Aspergillus antigens in cystic fibrosis. Acta Pathol Microbiol Immunol Scand Sect B 1985;93:105-12.

3 Greenberger PA, Miller T, Roberts M, et al. Allergic bronchopulmonary aspergillosis in patients with and without evidence of bronchiectasis. Ann Allergy 1993;70:333-8.

4 Pressler T, Mansa B, Jensen $\mathrm{T}$, et al. Increased $\mathrm{IgG}_{2}$ and $\mathrm{IgG}_{3}$ concentration is associated with advanced Pseudomonas aeruginosa and poor pulmonary function in cystic fibrosis. Acta Paediatr Scand 1988;77:576-82.

5 Schønheyder H, Andersen P, Stenderup A. Serum antibodies to Aspergillus fumigatus in patients with pulmonary ies to Aspergillus fumigatus in patients with pulmonary aspergillosis detected by immunofluorescence.

6 Wide L, Bennich H, Johansson SG. Diagnosis of allergy by an in-vitro test for allergen antibodies. Lancet 1967;ii: 1105-7.

7 Jensen HE, Aalbæk B, Lind P, et al. Development of murine monoclonal antibodies for the immunohistochemical diagnosis of systemic bovine aspergillosis. 7 Vet Diagn Invest 1996;8:68-75.

8 Pressler T, Pedersen SS, Espensen F, et al. IgG subclass antibodies to Pseudomonas aeruginosa in sera from patients with chronic $P$. aeruginosa infection investigated by enzyme linked immunosorbent assay. Clin Exp Immunol 1990;81: linked im 428 .

9 Forsgren A, Sjøquist J. "Protein A" from Staphylococcus aureus. I. Pseudoimmune reaction with human gammaglobulin. F Immunol 1966;99:822.

10 Metcalfe DD, Sampson HA. Workshop on experimental methodology for clinical studies of adverse reactions to food and food additives, Washington DC, November 1988. 7 Allergy Clin Immunol 1990;86:421-42.

11 Wilson EV, Hearn VM. Use of Aspergillus fumigatus mycelial antigens in enzyme-linked immunosorbent assay and counter-immunoelectrophoresis. F Med Microbiol 1983;16: 97-105.

12 Høiby N. Pseudomonas aeruginosa infection in cystic fibrosis. Diagnostic and prognostic significance of Pseudomonas aeruginosa precipitins determined by means of crossed immunoelectrophoresis. Acta Pathol Microbiol Scand Sect C 1977;262(Suppl): 1 .

13 Pedersen SS, Espersen F, Høiby N. Diagnosis of chronic Pseudomonas aeruginosa infection in cystic fibrosis by enzyme-linked immunosorbent assay. $f$ Clin Microbiol 1987;25:1830-6.

14 Nikolaizik WH, Moser M, Crameri R, et al. Identification of allergic bronchopulmonary aspergillosis in cystic fibrosis patients by recombinant Aspergillus fumigatus 1/a-specific serology. Am 7 Respir Crit Care Med 1995;152:634-9.

15 Knutsen AP, Mueller KR, Hutcheson PS, et al. Serum antiAspergillus fumigatus antibodies by immunoblot and ELISA in cystic fibrosis with allergic bronchopulmonary aspergillosis. F Allergy Clin Immunol 1994;93:926-31. 
16 El-Dahr JM, Fink R, Selden R, et al. Development of immune responses to Aspergillus at an early age in children with cys

17 Kurup VP, Resnick A, Kalbfleish J, et al. Antibody isotype responses in Aspergillus-induced diseases. 7 Lab Clin Med 1990;115:298-303.

18 Greenberger PA, Patterson R. Application of enzyme-linked immunosorbent assay (ELISA) in diagnosis of allergic bronchopulmonary aspergillosis. $\mathcal{F}$ Lab Clin Med 1982;99: 288-93.

19 Trompell J, Becker WM, Schlaak M. Analysis of IgG subclass and IgE response in allergic disease caused by Aspergillus fumigatus by immunoblotting tecniques. Int Arch Allergy Immunol 1994;104:390-8.
20 Tomee JFC, Dubois AE, Koeter GH, et al. Specific $\mathrm{IgG}_{4}$ responses during chronic and transient antigen exposure in aspergillosis. Am J Respir Crit Care Med 1996;153:1952-7. 1 Leser C, Kauffman HF, Virchow C, et al. Specific serum immunopattern in clinical phases of allergic bronchopulmonary aspergillosis. F Allergy Clin Immunol 1992;90:58999.

22 Leung PSC, Gerswin ME, Coppel R, et al. Localization, molecular weight and immunoglobulin subclass response to Aspergillus fumigatus allergens in acute bronchopulmonary aspergillosis. Int Arch Allergy Appl Immunol 1988;85: $416-21$

23 Forsyth KD, Hohmann AW, Martin AJ, et al. IgG antibodies to Aspergillus fumigatus in cystic fibrosis: a laboratory correlate of disease activity. Arch Dis Child 1988;63:953-7. 